Check for updates

Cite this: RSC Adv., 2018, 8, 11643

\title{
An environmentally sustainable plasticizer toughened polylactide
}

\author{
Hailan Kang, (D) a Yushi Li, ${ }^{a}$ Ming Gong, ${ }^{a}$ Yilin Guo, ${ }^{a}$ Zhuo Guo, ${ }^{a}$ Qinghong Fang ${ }^{\star a}$ \\ and Xue Li*b
}

Cardanol (CD), derived from renewable natural cashew nutshell liquid, has been used as a new plasticizer for polylactide (PLA), to create blends which retain the environmentally friendly features of PLA. The differential scanning calorimetry (DSC), dynamic mechanical thermal analysis (DMTA) and scanning electron microscopy (SEM) results all reveal that PLA and CD show good miscibility at low CD content. CD significantly decreased the glass transition temperature and enhanced the crystallization ability of PLA, demonstrating good plasticizing efficiency with PLA. At $10 \mathrm{wt} \% \mathrm{CD}$, ultimate elongation and impact toughness increased to $472 \%$ and $9.4 \mathrm{~kJ} \mathrm{~m}^{-2}$, respectively, which represented improvements of 31 -fold and 2.6-fold over the corresponding measurements for neat PLA. The plasticization effect of CD was also demonstrated by the decreased melt complex viscosity and shear storage modulus at lower CD content for the blends when compared with neat PLA. Thus, the investigated CD presents an interesting candidate for a PLA plasticizer, meeting "double green" criteria. No cytotoxicity was found for the blends and hence they may be suitable for biomedical applications.

Received 19th December 2017 Accepted 22nd February 2018

DOI: $10.1039 / c 7 r a 13448 g$

rsc.li/rsc-advances relatively low boiling points resulted in considerable weight loss during processing. Other ester-type plasticizers, such as glycerin triacetate (GTA) and bis(2-ethylhexyl) adipate (DOA), were effective in reducing the $T_{\mathrm{g}}$ of the blend but PLA plasticized with $\sim 25 \mathrm{wt} \%$ GTA $^{18}$ or $20 \mathrm{wt} \% \mathrm{DOA}^{19}$ exhibited phase separation. Oligomeric or polymeric plasticizers could reduce the migration and evaporation of the small molecule plasticizers and many studies have paid attention to the utilization of poly(ethylene glycol) (PEG) for PLA. $^{\text {20,21 }}$ The molecular weight as well as the additive amount of PEG influences the miscibility between PLA and PEG. The PLA/ PEG blends with lower molecular weight PEG exhibited better miscibility, reducing the $T_{\mathrm{g}}$ to a greater extent. Modification of PLA has also been achieved via the addition of lactide monomers, ${ }^{22}$ soybean oil derivatives, ${ }^{23,24}$ castor oil derivatives, ${ }^{25,26}$ tartaric acid derivatives $^{27}$ and so on. However, the challenge remains to find a new renewable plasticizer meeting the requirements of both a sustainable origin and biodegradable properties, to fulfill "double green" criteria.

Cardanol ( $m$-pentadecenyl phenol, CD) is a type of renewable agricultural by-product extracted from cashew nutshell liquid. ${ }^{28}$ CD has desirable features due to its chemical structure: (i) the benzene ring structure leads to high-temperature performance; (ii) the polar phenol hydroxyl group provides wetting and activity to the contact surface; and (iii) the long unsaturated side chain with 15 carbon atoms endows $C D$ with excellent flexibility and reactivity. The structure is shown in Fig. 1. CD and its derivatives are used as additives in biocomposites, ${ }^{29}$ synthetic plastics, ${ }^{30,31}$ and rubbers $^{32}$ owing to their sustainability, low cost, biodegradability, and significant antioxidant
${ }^{a}$ College of Materials Science and Engineering, Shenyang University of Chemical Technology, Shenyang, 110142, China. E-mail: fqh80@126.com

${ }^{b}$ Department of Chemistry and Textile Engineering, Jiaxing University Nanhu College, Jiaxing, 314001, China. E-mail: lixue850704@163.com 
<smiles>[R]c1cccc(O)c1</smiles>

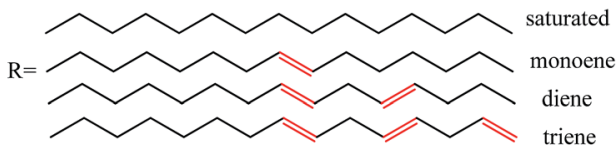

Fig. 1 Structure of cardanol.

characteristics. Mohapatra and $\mathrm{Nando}^{32}$ developed CD grafted natural rubber with a higher molecular weight, a higher cure rate and better physical-mechanical properties than unmodified natural rubber. Chen et $a l .^{33}$ reported that CD-based derivatives are more efficient than dioctyl phthalate in plasticizing PVC.

CD-derivatives, such as di-functional glycidyl ether epoxy cardanol (ECD) or methoxylated hydroxyethyl cardanol (MeCD), have been used as plasticizers for PLA by Hassouna and coworkers. ${ }^{34,35}$ However, there are no detailed studies of $\mathrm{CD}$ as the PLA modifier. CD is a commercial product and meets the "double green" criteria. Importantly, the existence of $-\mathrm{OH}$ groups in both CD and PLA implies some compatibility between PLA and CD. Thus, we employ CD as a PLA plasticizer and develop environmentally sustainable PLA/CD blends. In this work, the miscibility, thermal and crystallization behaviors, mechanical properties, processability and cytocompatibility of PLA/CD blends are analyzed and investigated in detail.

\section{Experimental section}

\section{Materials}

The polylactide (PLA, Grade 2003D) was provided by Nature Works and dried for $24 \mathrm{~h}$ in a vacuum oven at $60{ }^{\circ} \mathrm{C}$ before use. Cardanol (CD, purity of 98\%) was purchased from Jining Hongming Chemical Reagent Co., Ltd (China). Antioxidant 1010 was purchased from Sinopharm Chemical Reagent Co., Ltd. Mouse preosteoblasts (MC3T3-E1) were kindly donated by Beijing Jishuitan Hospital (China).

\section{Preparation of PLA/CD blends}

PLA, CD and antioxidant 1010 (0.3 wt\%) were mixed at 170$180{ }^{\circ} \mathrm{C}$ in a torque rheometer for $10 \mathrm{~min}$ at a rotation speed of $80 \mathrm{rpm}$. The weight ratios of CD to PLA were varied from $0 \mathrm{wt} \%$ to $30 \mathrm{wt} \%$. For brevity, the blend containing $10 \mathrm{wt} \% \mathrm{CD}$ was abbreviated to PLA/CD-10. Finally, the samples were compressed into $1 \mathrm{~mm}$ thick sheets at $180{ }^{\circ} \mathrm{C}$ for $5 \mathrm{~min}$, and were then cold-pressed.

\section{Characterization}

DSC measurement was carried out under $\mathrm{N}_{2}$ with a Q200 differential scanning calorimeter (TA Instruments). The specimens were first heated to $190{ }^{\circ} \mathrm{C}$, then cooled to $0{ }^{\circ} \mathrm{C}$, and finally reheated to $190{ }^{\circ} \mathrm{C}$ at $10{ }^{\circ} \mathrm{C} \mathrm{min}^{-1}$. The quenched specimens were directly cooled to $-80^{\circ} \mathrm{C}$, and heated to $190^{\circ} \mathrm{C}$ at $10^{\circ} \mathrm{C} \mathrm{min}^{-1}$. The degree of crystallinity of PLA was calculated using the enthalpy of fusion of $100 \%$ crystalline PLA, equal to $93 \mathrm{~J} \mathrm{~g}^{-1} \cdot{ }^{36}$ Gold-coated sample surfaces were characterized by a SU8010 scanning electron microscope (Hitachi Co., Ltd) at $5 \mathrm{kV}$.

Dynamic mechanical thermal analysis (DMTA) was performed on a dynamic mechanical analyzer (PE Instruments) in tensile mode at $1 \mathrm{~Hz}$ and at a heating rate of $3{ }^{\circ} \mathrm{C} \min ^{-1}$ from $-100{ }^{\circ} \mathrm{C}$ to $150{ }^{\circ} \mathrm{C}$. Wide-angle X-ray diffraction (WAXD) was performed on a Rigaku RINT diffractometer with $\mathrm{Cu} \mathrm{K} \alpha$ radiation $(40 \mathrm{kV}, 200 \mathrm{~mA})$ in the $2 \theta$ range of $5^{\circ}$ to $50^{\circ}$ at a scan rate of $5^{\circ} \mathrm{min}^{-1}$. Thermogravimetric analysis (TGA, Q50, TA Instruments) was used to investigate the thermal decomposition behavior. The TGA measurements were carried out from 40 to $600{ }^{\circ} \mathrm{C}$ at a heating rate of $20{ }^{\circ} \mathrm{C} \min ^{-1}$ under $\mathrm{N}_{2}$.

The tensile properties of the PLA/CD blends were tested by using a RGL-3UA tensile testing machine according to ASTM D638 at a crosshead speed of $10 \mathrm{~mm} \mathrm{~min}^{-1}$. The notched Izod impact tests were performed on a Gotech impact machine according to ASTM D256. Rheological experiments were measured on an ARES-G2 rotational rheometer (TA Instruments) in frequency sweep mode from 0.1 to $100 \mathrm{~Hz}$ at $180^{\circ} \mathrm{C}$ with a strain of $1 \%$.
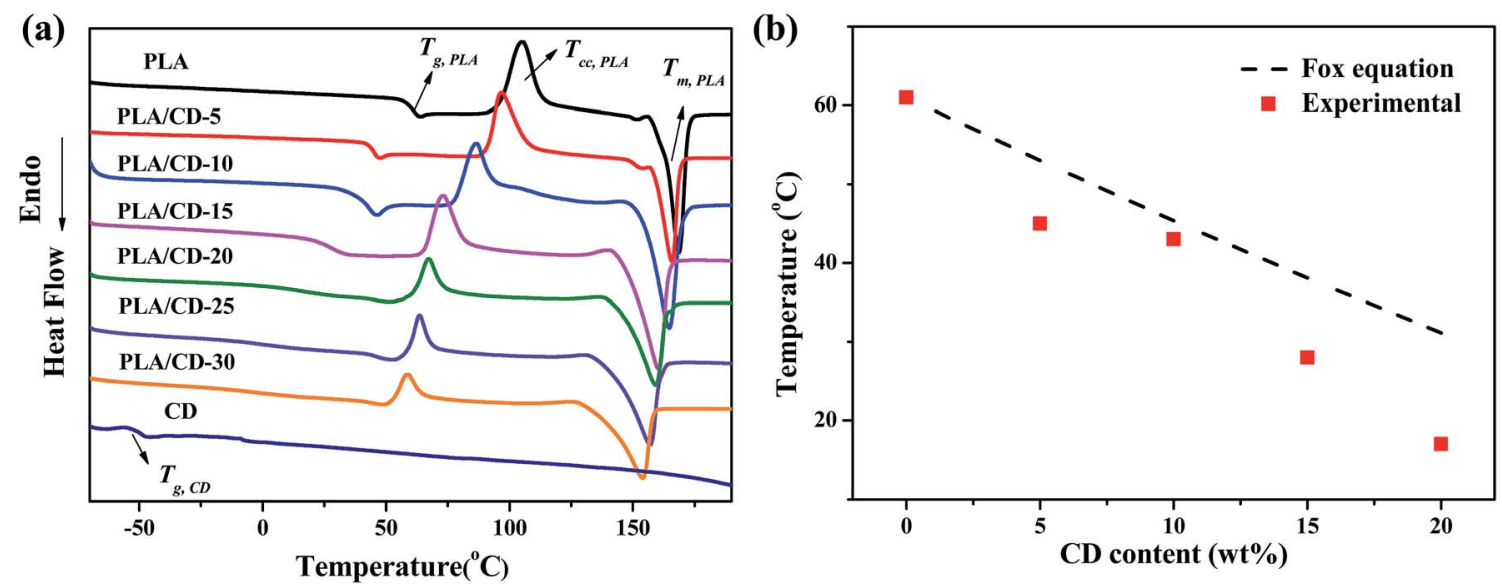

Fig. 2 (a) DSC thermograms of PLA, PLA/CD blends and CD; (b) plot of glass transition temperature vs CD content. 
Cell viability was measured using mouse preosteoblasts (MC3T3-E1) and 3-(4,5-di-methylthiazol-2-yl)-2,5-diphenyltetrazolium bromide (MTT) assays. All samples were cut into slices, sterilized by washing with $75 \%$ ethanol, and then rinsed twice with PBS solution. Samples were exposed to $\mathrm{Co}^{60}$ for $15 \mathrm{~min}$ and incubated in Dulbecco's modified Eagle's medium (DMEM) at the ratio of $3 \mathrm{~cm}^{2} \mathrm{~mL}^{-1}$ for $24 \mathrm{~h}$ at $37^{\circ} \mathrm{C}$. The extract solutions were then filtered $(0.22 \mu \mathrm{m}$ pore size $)$ to eliminate the possible presence of solid particles in the samples. MC3T3-E1 cells were grown in DMEM supplemented with $10 \%$ fetal bovine serum (FBS) at a density of $5.0 \times 10^{4}$ cells per well and incubated in $5 \% \mathrm{CO}_{2}$ under humidified conditions at $37^{\circ} \mathrm{C}$. After the incubation, the medium was replaced by the prepared extract dilution which was used as the new culture medium, while the initial medium itself was regarded as a negative control. The cells were allowed to proliferate for 3 days, and the number of viable cells was determined by adding $5 \mathrm{mg} \mathrm{mL}{ }^{-1}$ MTT in culture medium. After a further incubation of $4 \mathrm{~h}$, the medium was aspirated, the formed blue formazan crystals were dissolved in isopropanol (BDH, Poole, England), and the absorbance at $450 \mathrm{~nm}$ was determined. All sample extracts were tested at least three times to obtain consistent results. The relative viability was calculated by:

$$
\text { Relative cell viability }=\left(A_{\text {test }}-A_{0}\right) /\left(A_{\text {control }}-A_{0}\right)
$$

where $A_{\text {control }}$ refers to the absorbance of the control wells containing cells with DMEM, and $A_{0}$ refers to the absorbance of the solution containing only DMEM. The morphology of the cells after incubation for 3 days was observed using an inverted phase contrast microscope before the MTT testing.

\section{Result and discussion}

\section{Miscibility and morphology}

The miscibility of the polymer blends was characterized and analyzed using the $T_{\mathrm{g}}$ values of blends of various compositions. We quenched the molten samples by immersion into liquid nitrogen, and the DSC curves obtained from the quenched samples are shown in Fig. 2a. The PLA exhibited a $T_{\mathrm{g}}$ value of around $61{ }^{\circ} \mathrm{C}$. All blends exhibited only one $T_{\mathrm{g}}$, suggesting a good miscibility between PLA and CD. The $T_{\mathrm{g}}$ of the PLA/CD blend dropped significantly with increasing CD content, most likely demonstrating good plasticizing efficiency with PLA. For instance, the $T_{\mathrm{g}}$ value of PLA decreased by $43{ }^{\circ} \mathrm{C}$ and $17{ }^{\circ} \mathrm{C}$ for PLA/CD-10 and PLA/CD-20, respectively. As the content of CD was increased to $20 \mathrm{wt} \%$, the $T_{\mathrm{g}}$ peak became very broad and nearly indistinguishable. Thus, the content of CD in the blends is below $20 \mathrm{wt} \%$ in the following discussion.

The $T_{\mathrm{g}}$ values obtained from DSC are plotted in Fig. $2 \mathrm{~b}$ according to the Fox equation ${ }^{37}$

$$
\frac{1}{T_{\mathrm{g}}}=\frac{w_{1}}{T_{\mathrm{g}_{1}}}+\frac{w_{2}}{T_{\mathrm{g}_{2}}}
$$

where $w$ is the weight fraction and the subscripts 1 and 2 indicate polymer 1 and 2, respectively. The $T_{\mathrm{g}} \mathrm{s}$ of the quenched PLA/CD blends show a negative deviation from the empirical Fox equation. It was inferred that small molecule plasticizers move into PLA polymer chains, greatly increase the free volume of the molecular chains, and thus improve the chain mobility of the polymer, resulting in the obvious decrease in $T_{\mathrm{g}}$.

Scanning electron microscopy (SEM) was employed to further evaluate miscibility and phase morphology. Fig. 3 shows the SEM micrographs for cryo-fractured surfaces of the PLA/CD blends. As shown in Fig. 3a and b, PLA/CD-5 and PLA/CD-10 exhibit rough surfaces and few voids can be observed, suggesting that CD is only partially miscible with PLA at lower content. A partially miscible system should exhibit two $T_{\mathrm{g}}$ peaks in the DSC curves. However, a $T_{\mathrm{g}}$ peak attributing to CD was not detected, owing to the relatively low CD content in the blends and the limitations of the DSC technique. As we know, the DSC equipment is insensitive to low enthalpy changes at a slow scanning rate. For PLA/CD-15, PLA/CD-20 and PLA/CD-25, no
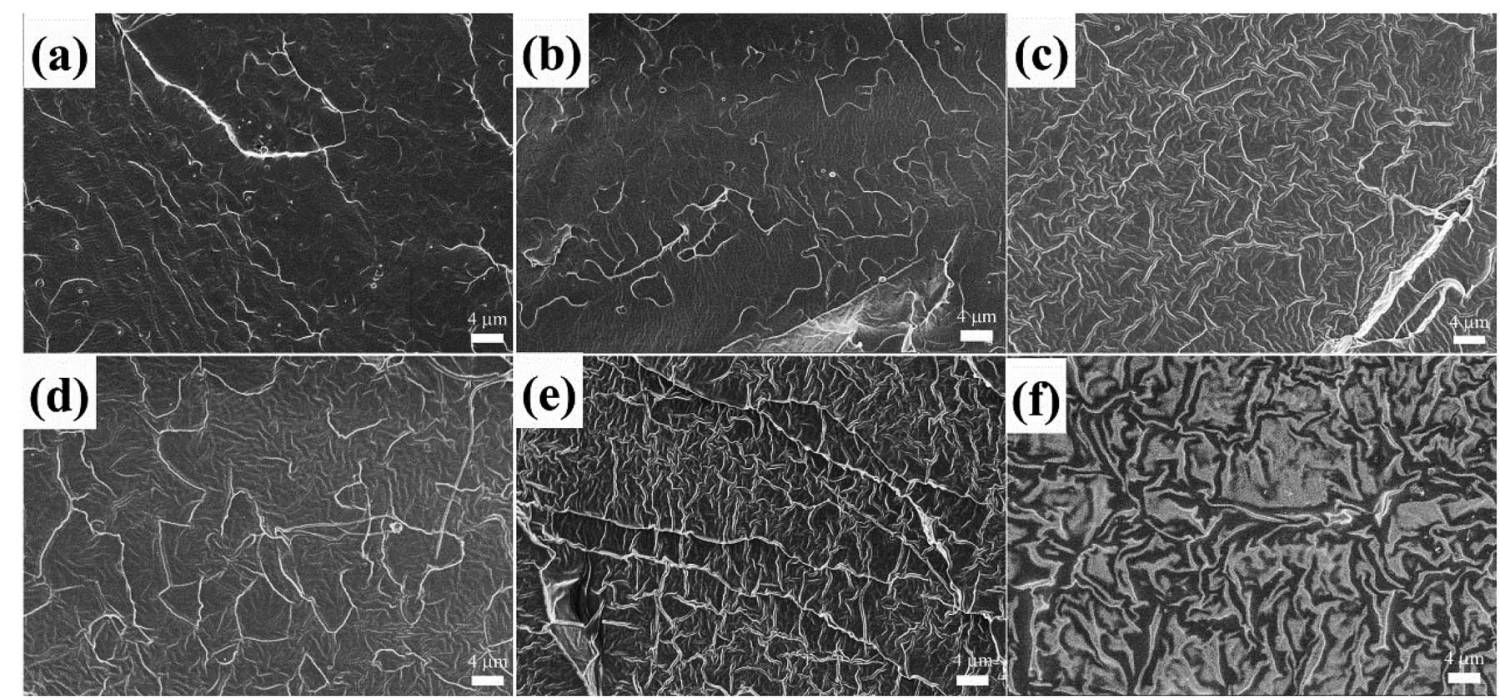

Fig. 3 SEM micrographs for cryo-fractured surfaces of PLA/CD blends: (a)PLA/CD-5; (b) PLA/CD-10; (c)PLA/CD-15; (d) PLA/CD-20; (e)PLA/CD25; (f) PLA/CD-30. 
(a)

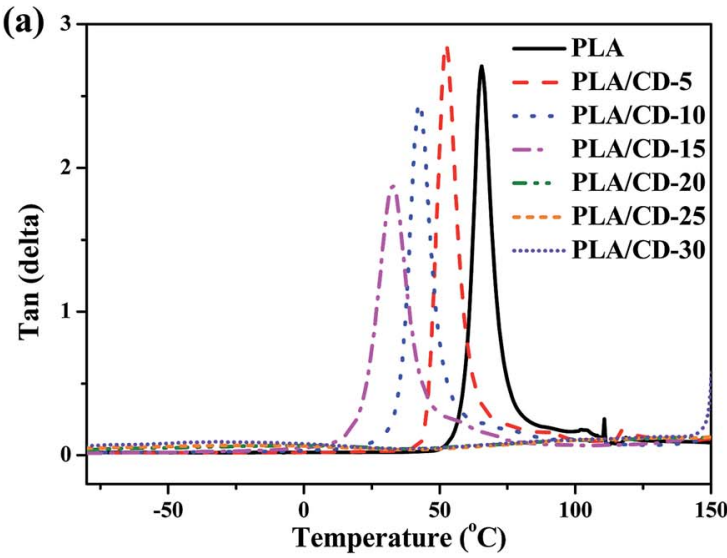

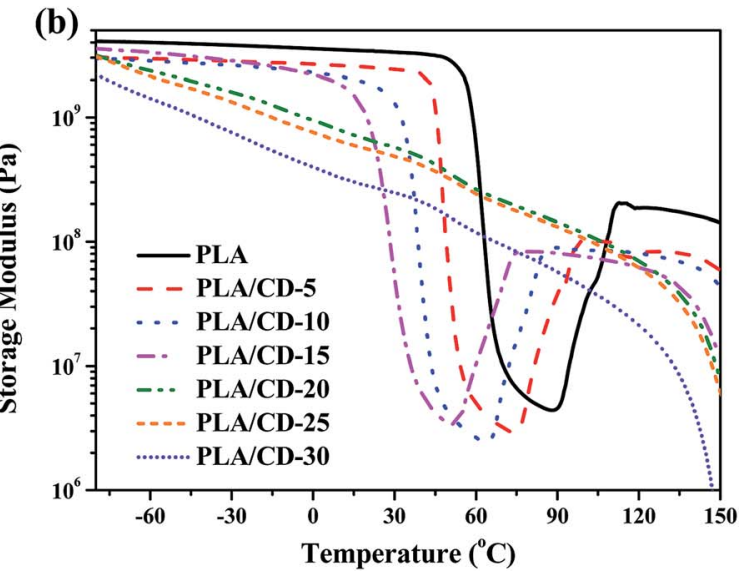

Fig. 4 Dynamic viscoelastic curves of PLA and PLA/CD blends: (a) tan $\delta$ versus temperature; (b) storage modulus versus temperature.

voids can be seen (Fig. 3c-e) and phase separation does not occur, indicating that $\mathrm{CD}$ is miscible with PLA. Since small molecule plasticizers migrate toward the surfaces during storage (about 20 days), the surface of PLA/CD-30 is very obscure and phase separation occurs.

\section{Dynamic mechanical thermal analysis}

Fig. 4 shows the $\tan$ delta $(\tan \delta)$ and tensile storage modulus $\left(E^{\prime}\right)$ as a function of temperature for the blends. In Fig. 4a, the temperature at the maximum value of $\tan \delta$ corresponds to the $T_{\mathrm{g}}$. The PLA/CD blends show only one $T_{\mathrm{g}}$ when the CD content is lower than $15 \mathrm{wt} \%$, and the $T_{\mathrm{g}}$ values of PLA/CD blends distinctly shift to the lower temperature region with increasing CD content, in line with the aforementioned DSC analysis. The single $T_{\mathrm{g}}$ for each sample and the reduction in $T_{\mathrm{g}}$ with increasing CD content both indicate that PLA is miscible with CD. No peak was observed for the PLA/CD blends with CD content higher than $15 \mathrm{wt} \%$, because the blends had already attained high crystallinity.

As shown in Fig. 4b, the $E^{\prime}$ of PLA drops sharply at around $54-75{ }^{\circ} \mathrm{C}$ due to the glass transition, then rises at around $90{ }^{\circ} \mathrm{C}$ due to cold crystallization, and subsequently drops again at around $125{ }^{\circ} \mathrm{C}$ due to crystal melting. For the PLA/CD blends, the $E^{\prime}$ curves show two very different trends. When the $\mathrm{CD}$ content is lower than $15 \mathrm{wt} \%$, the trend of the $E^{\prime}$ curves for the PLA/CD blends is similar to that for PLA. The $E^{\prime}$ at the glassy state gradually decreases with increasing CD content. The temperature at which $E^{\prime}$ starts to rise shifts to a lower temperature region with increasing $\mathrm{CD}$ content, indicating that the introduction of $\mathrm{CD}$ enhances the cold crystallization ability of PLA. In contrast, when the CD content is higher than $15 \mathrm{wt} \%$, the $E^{\prime}$ of the PLA/CD blends decreases with both temperature and CD content. A rise of $E^{\prime}$ due to the cold crystallization of PLA is not observed, suggesting that the molded sample has already attained almost the ultimate crystallinity before the dynamic viscoelastic test.

\section{Thermal and crystalline behaviors}

The DSC curves of PLA and its blends are exhibited in Fig. 5, and the relevant results obtained from the DSC curves are summarized in Table 1. Upon heating, PLA shows a clear glass transition at $61{ }^{\circ} \mathrm{C}$, a cold-crystallizing peak at $105{ }^{\circ} \mathrm{C}$ and a melting peak at $168^{\circ} \mathrm{C}$ (Fig. 5b). As shown in Fig. 5b, the PLA/CD blends cold-crystallize at $70-96{ }^{\circ} \mathrm{C}$, and the cold crystallization
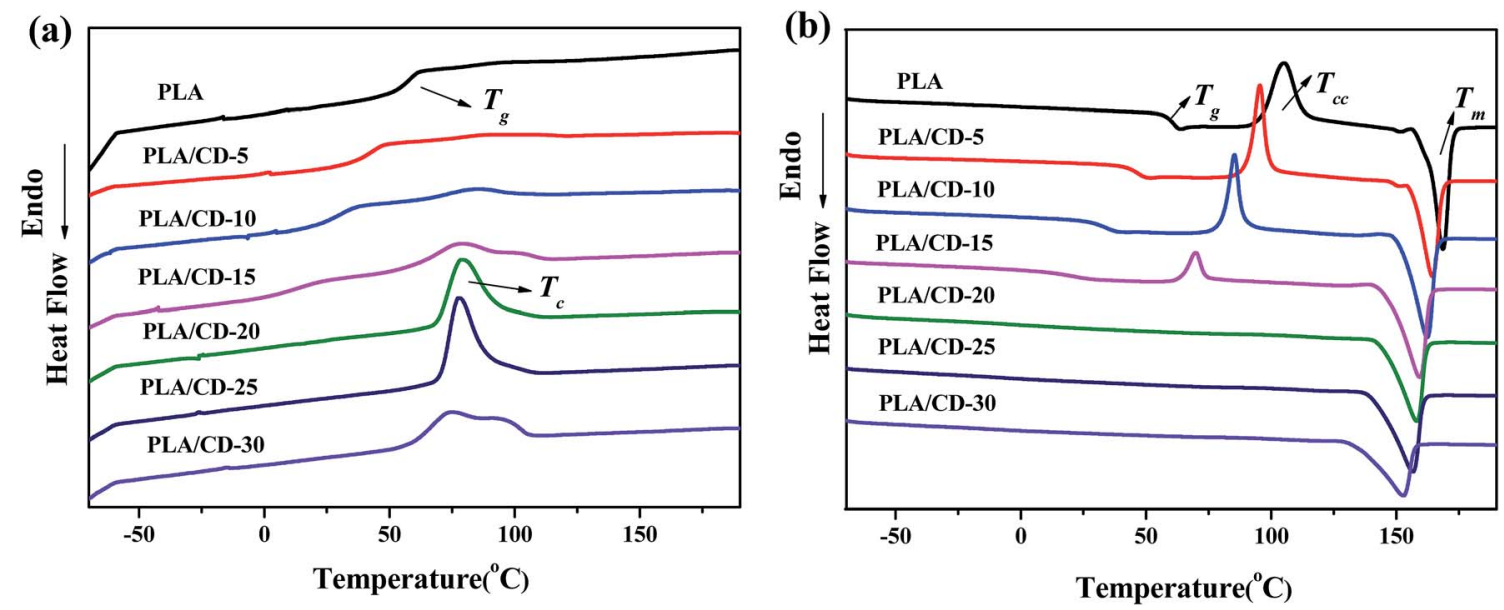

Fig. 5 DSC thermograms of PLA and PLA/CD blends: (a) cooling; (b) heating. 
Table 1 Thermal properties of PLA, PLA/CD blends and CD ${ }^{a}$

\begin{tabular}{|c|c|c|c|c|c|c|c|c|}
\hline $\begin{array}{l}\text { CD content } \\
(\%)\end{array}$ & $T_{\mathrm{g}}\left({ }^{\circ} \mathrm{C}\right)$ & $T_{\mathrm{c}}\left({ }^{\circ} \mathrm{C}\right)$ & $\Delta H_{\mathrm{c}}\left(\mathrm{J} \mathrm{g}^{-1}\right)$ & $T_{\mathrm{cc}}\left({ }^{\circ} \mathrm{C}\right)$ & $\Delta H_{\mathrm{cc}}\left(\mathrm{J} \mathrm{g}^{-1}\right)$ & $T_{\mathrm{m}}\left({ }^{\circ} \mathrm{C}\right)$ & $\Delta H_{\mathrm{m}}\left(\mathrm{J} \mathrm{g}^{-1}\right)$ & Crystallinity (\%) \\
\hline 0 & 61 & - & - & 105 & 33.2 & 169 & 33.7 & 0.5 \\
\hline 10 & 43 & 85 & 6.1 & 85 & 25.8 & 162 & 37.8 & 12.9 \\
\hline 15 & 28 & 78 & 16.1 & 70 & 12.5 & 159 & 39.2 & 28.7 \\
\hline 20 & 15 & 78 & 33.1 & - & - & 158 & 40.4 & 43.4 \\
\hline 100 & -50 & - & - & - & - & - & - & - \\
\hline
\end{tabular}

${ }^{a} T_{\mathrm{g}}$ was obtained from the quenched samples; the values of $\Delta H_{\mathrm{c}}, \Delta H_{\mathrm{cc}}, \Delta H_{\mathrm{m}}$ were normalized; the crystallinity was calculated by DSC curves.

temperature $\left(T_{\mathrm{cc}}\right)$ of PLA decreases as the CD content increases. When the CD content is higher than $15 \mathrm{wt} \%$, the coldcrystallizing peak cannot be observed, but the PLA/CD blends exhibit a sharp and intense crystallization peak during cooling. The higher CD content shifts the crystallizing peak to a lower temperature, and increases the heat of crystallization $\left(\Delta H_{\mathrm{c}}\right)$ to a higher value. This phenomenon can be ascribed to two main factors: (1) the increased chain mobility which enables PLA to crystallize at a lower temperature upon cooling; (2) the role of the plasticizer as a nucleating agent. Similarly, the melting temperature $\left(T_{\mathrm{m}}\right)$ shifts to a lower temperature by 5 to $16{ }^{\circ} \mathrm{C}$ and the enthalpy of fusion increases with increasing $\mathrm{CD}$ content. In parallel, the degree of crystallinity increases from $1 \%$ to $46 \%$, similarly showing that the enhanced chain mobility increases the ability of the PLA chains to crystallize.

Wide-angle X-ray diffraction (WAXD) spectra were employed to further investigate the crystallization behavior of the PLA/CD blends. As seen in Fig. 6, PLA shows an amorphous structure with no diffraction peaks. PLA/CD blends containing lower CD content, display no diffraction peaks, suggesting that the blends are primarily amorphous. However, diffraction peaks of PLA/CD blends appear and become more intense with the addition of more $\mathrm{CD}$, consistent with the DSC results. When the CD content is higher than $15 \mathrm{wt} \%$, a diffraction peak at $2 \theta \approx 16.5^{\circ}$ appears,

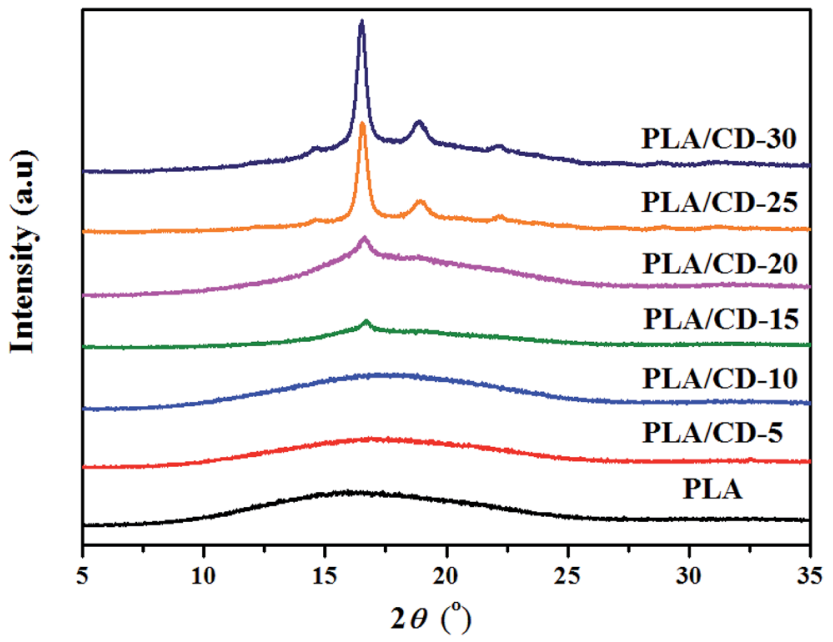

Fig. 6 WAXD curves of PLA and PLA/CD blends. corresponding to the $(110 / 200)$ crystalline plane of $\alpha^{\prime}$ or $\alpha$ crystal forms. ${ }^{38}$ In addition, diffraction peaks at around $14.6^{\circ}, 18.8^{\circ}$ and $22.2^{\circ}$ are detected, relating to the (010), (203) and (015) planes, respectively. ${ }^{38}$

We also investigated the thermal stability of the PLA/CD blends, and the TGA curves are shown in Fig. 7. The thermal decomposition of neat PLA begins at about $320^{\circ} \mathrm{C}$ and reaches a maximum degradation rate at about $398{ }^{\circ} \mathrm{C}$, while thermal decomposition of $\mathrm{CD}$ begins at about $220{ }^{\circ} \mathrm{C}$ and reaches a maximum degradation rate at about $340{ }^{\circ} \mathrm{C}$. All the blends reveal a single stage decomposition at $290-420{ }^{\circ} \mathrm{C}$, and a maximum degradation rate at $387-398{ }^{\circ} \mathrm{C}$, similar to that of neat PLA. For the PLA/CD blends, the thermal decomposition starts at a lower temperature compared with that of PLA. Therefore, the addition of CD slightly influences the thermal stability of PLA, but it meets the requirements of most applications.

\section{Mechanical properties}

The stress-strain behavior of the PLA/CD blends was tested at room temperature, as shown in Fig. 8a. Neat PLA fractures without yielding, exhibiting as a brittle material with a high tensile strength of $52.4 \mathrm{MPa}$ and a low elongation at break of $15 \%$. For PLA/CD-10, a pronounced yield followed by a stable

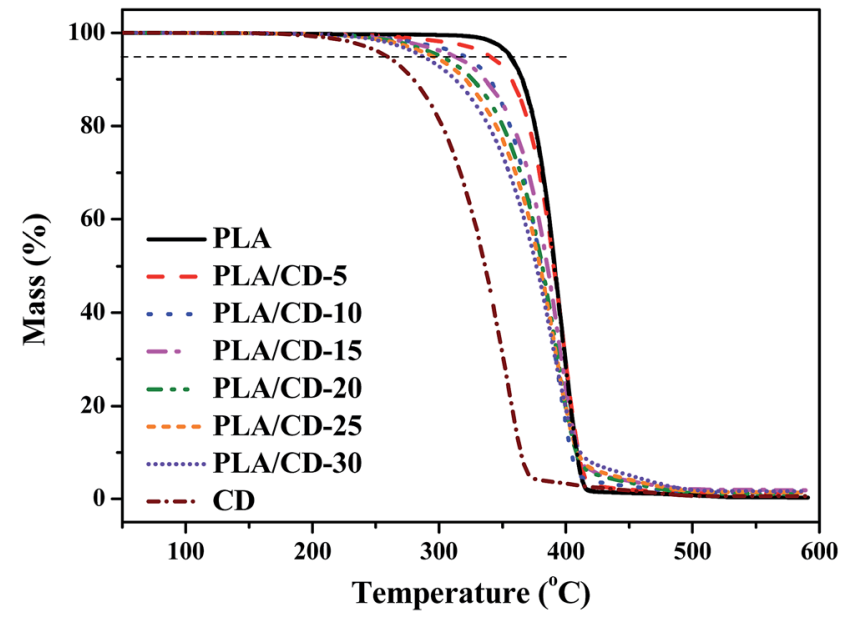

Fig. 7 TGA thermograms of PLA, PLA/CD blends and CD. 
(a)

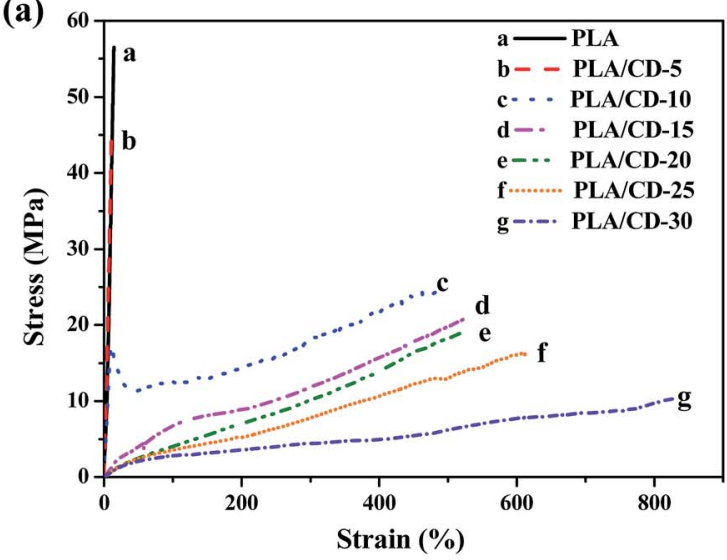

(b)

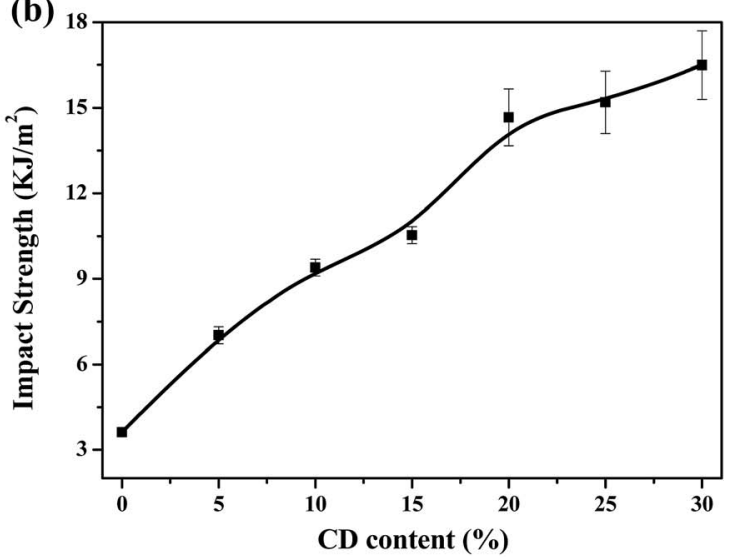

Fig. 8 (a) The stress-strain curves of PLA/CD blends; (b) effect of CD content in the blends on impact strength.

neck is observed; the tensile strength drops to $25.1 \mathrm{MPa}$ and the elongation at break increases to $472 \%$, representing a 31 -fold improvement over the value for neat PLA. The increase of CD content to $15 \mathrm{wt} \%$ further decreases the tensile strength to about 22.5 MPa, while no yield point is found. Thus, the PLA/CD blends containing more than $15 \mathrm{wt} \% \mathrm{CD}$ exhibit the stretch behavior of elastomers. Such material flexibility improvement is directly related to the significant increase in chain mobility. The tensile strength and tensile modulus of blends decrease with increasing $\mathrm{CD}$ content, which can be reasonably explained by the introduction of small molecules. Thus, the addition of plasticizers causes a decrease in the tensile modulus and tensile strength and an increase in the elongation at break for all the blends. Compared with CD derivatives, the increase in elongation at break of our PLA/CD blend (from $15 \%$ to $472 \%, 31$ times) may surpass that found in the previous studies on the toughening of PLA. For example, the elongation at break of a PLA/ methoxylated hydroxyethyl cardanol blend increased from $12 \%$ to $198 \%, 16.5$ times that of neat PLA. ${ }^{35}$ For a PLA/difunctional glycidyl ether epoxy cardanol blend prepared through in situ reactive grafting, the elongation at break increased from $5.7 \%$ to $49 \%{ }^{34}$

The impact strength represents the ability of a material to absorb fracture energy during an impact process. The most common and useful measurement of impact strength is the notched impact strength. Therefore, we adopted the notched Izod impact test to characterize the effect of $\mathrm{CD}$ on impact toughness. As shown in Fig. 8b, the notched Izod impact strength increases markedly with CD content, and reaches its maximum value at $30 \mathrm{wt} \% \mathrm{CD}$. The maximum impact strength is $16.5 \mathrm{~kJ}$ $\mathrm{m}^{-2}$, a 4.6-fold improvement compared to that of neat PLA.

To identify the toughening effect of CD on PLA/CD blends, the impact-fractured surfaces were studied by SEM. For PLA (Fig. 9a), smooth surfaces with no matrix deformation were

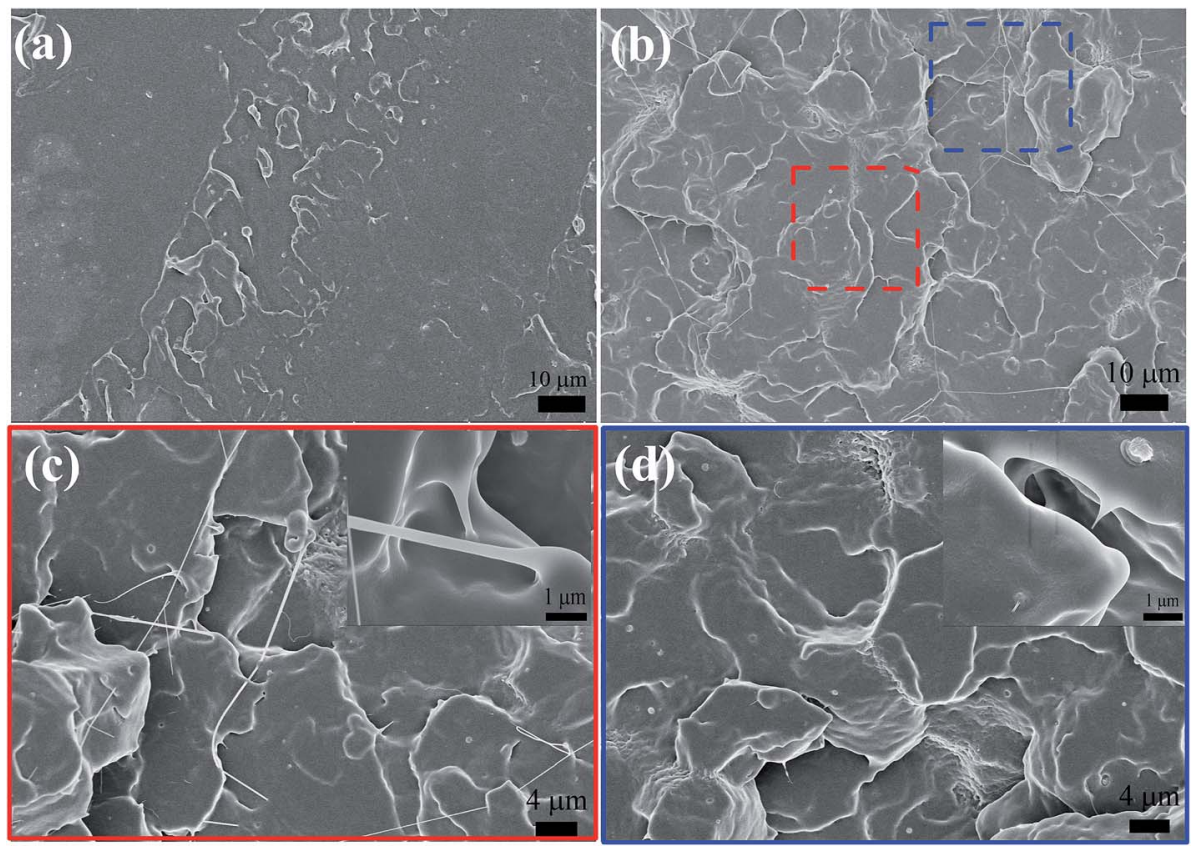

Fig. 9 SEM micrographs for impact-fractured surfaces of PLA/CD blends: (a) PLA; (b), (c) and (d) PLA/CD-10. 
(a)

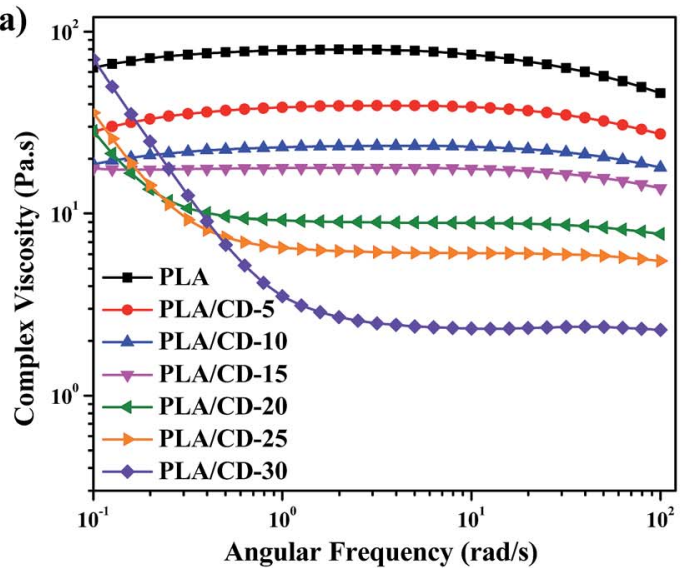

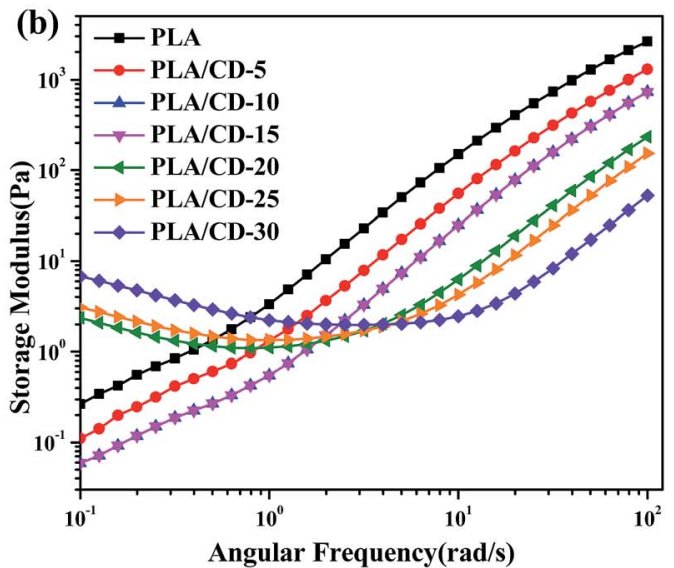

Fig. 10 Variation of complex viscosity (a) and storage modulus (b) versus angular frequency at $180^{\circ} \mathrm{C}$ for PLA and PLA/CD.

Table 2 Relationship between cell relative growth rate (RGR) and cytotoxicity grade of a material

\begin{tabular}{ccccccc}
\hline RGR (\%) & $\geq 100$ & $75-99$ & $50-74$ & $25-49$ & $1-24$ & 0 \\
Cytotoxicity grade & 0 & 1 & 2 & 3 & 4 & 5
\end{tabular}

found, indicating brittle failure. As shown in Fig. 9b, the fracture surfaces were rough and exhibited some matrix deformation, demonstrating ductile fracture. Under an applied stress, crazes were initiated and propagated outwards to the maximum applied stress. Craze growth was borne by the presence of bridging fibrils (Fig. 9c). For PLA/CD blends, some voids were observed, as shown in Fig. 9d. These voids, forming by cracks, expanded slowly by the breakdown of the surrounding craze fibrils until a void became a crack of a critical size that could propagate catastrophically. PLA/CD blends absorbed more energy than PLA during the process of craze growth, owing to the improved chain mobility.

\section{Rheological properties}

To investigate the effect of CD content on the melt rheological properties, frequency sweeps were carried out at $180^{\circ} \mathrm{C}$. Fig. 10a and $\mathrm{b}$ present the frequency dependences of complex viscosity $\left(\eta^{*}\right)$ and the shear storage modulus $\left(G^{\prime}\right)$ of PLA and PLA/CD blends, respectively. The PLA/CD blends display a lower viscosity and more obvious shear thinning behavior than PLA. Two types of complex viscosity curves can be observed. When the $\mathrm{CD}$ content is lower than $15 \mathrm{wt} \%$, an obvious newtonian plateau is observed in the low frequency region and a reduction in complex viscosity occurs in the high frequency region. In contrast, the blends with high $\mathrm{CD}$ content (above $15 \mathrm{wt} \%$ ) exhibit stronger shear thinning behavior with increasing $\mathrm{CD}$ content in the low frequency region. The decreased melt viscosity of the blend is ascribed to an increased free volume due to the plasticization by CD.

The shear storage modulus $\left(G^{\prime}\right)$ is sensitive to the composition of the PLA/CD blends, and increases with increasing frequency. $G^{\prime}$ increases with decreasing CD content. The blends with low CD content (below $15 \mathrm{wt} \%$ ) show lower $G^{\prime}$ values than PLA across the full frequency range. $G^{\prime}$ values exhibit an apparent plateau in the low frequency region when the $\mathrm{CD}$ content is increased to above $15 \mathrm{wt} \%$. Generally, $G^{\prime}$ is related to the elasticity of the microstructure, and the enhancement in $G^{\prime}$ represents the enhanced elastic response of the melt under shear conditions.

\section{Cytocompatibility}

The cytotoxicity of PLA/CD blends was evaluated to determine their suitability for biomedical applications. MC3T3-E1 cells were used
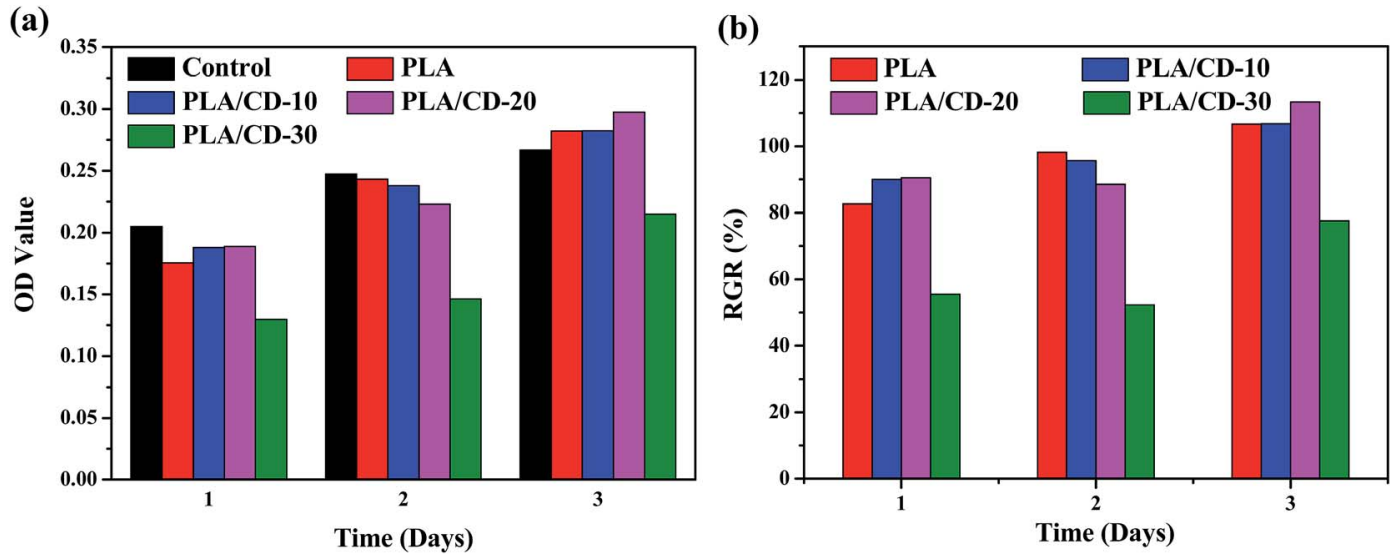

Fig. 11 Optical density (OD) value (a) and relative growth rate (RGR/\%) (b) of MC3T3-E1 cells cultured on PLA and PLA/CD blends compared with that on control substrate. 

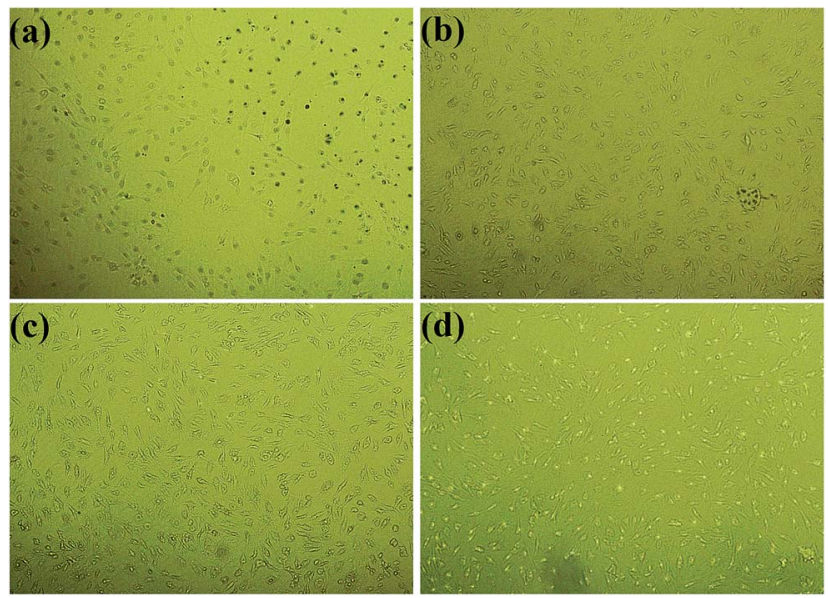

Fig. 12 Photomicrographs of MC3T3-E1 cells incubated for 3 days in the negative control (a), and the extract substrates of (b) PLA, (c) PLA/ CD-10 (d) PLA/CD-20.

in our cytotoxicity assays; the number and morphology of the cells in the extracts were observed. The values of optical density (OD) correspond to the number of live cells in the extract. Based on the cell relative growth rates (RGR) calculated from the OD values, the cytotoxicity of materials can be classified into six grades, shown in Table 2. Grades 0 and 1 mean that the material presents no or very low cytotoxicity to cells, and can be accepted as "qualified" in biomedicine. A material with Grade 2 should be further considered by examining its cell morphology. Other grades are regarded as "unqualified," indicating that the material presents very high cytotoxicity and cannot be used as a biomaterial. The OD values and RGR for neat PLA and PLA/CD blends are shown in Fig. 11. The OD values of the cells incubated on the substrates increased with time and even outnumbered that from the control after incubation for 3 days. The RGR values of the cells cultured on the blend substrates for 3 days were above $100 \%$ and were characterized as grade 0 except for PLA/CD-30. Therefore it is concluded that PLA/CD blends with low CD content show no toxicity to cell viability. As seen in Fig. 12, MC3T3-E1 cells show a normal stellate morphology and exhibit no negative response to PLA/CD blends with low $\mathrm{CD}$ content after incubation for 3 days, suggesting no cytotoxicity and the potential biocompatibility of the PLA/CD blends.

\section{Conclusions}

Renewable blends were prepared by the melt mixing of PLA and CD. DSC and SEM micrographs showed that PLA and CD exhibit good miscibility when the CD content is below $25 \mathrm{wt} \%$. The DSC results showed that blending PLA with CD reduced significantly the $T_{\mathrm{g}}$ value of the resulting polymer blend, in comparison to that of pure PLA. The crystallization ability of PLA was improved by incorporating $\mathrm{CD}$ due to the enhanced chain mobility. The addition of CD slightly reduced the thermal stability of the blends. Considering its good plasticizing efficiency and comprehensive mechanical properties, the PLA/CD blend with $10 \mathrm{wt} \% \mathrm{CD}$ was identified as the optimal formulation. At this optimal formulation, the elongation at break was significantly enhanced by 31-fold to $472 \%$ when compared to pure PLA; meanwhile, the impact toughness was improved by 2.6 -fold. The obvious plastic deformation, decreased melt viscosity and shear storage modulus of the blends demonstrated the excellent plasticization effect of CD. In vitro cytotoxicity tests showed that these PLA/CD composites are non-toxic towards MC3T3-E1 cells. Collectively, these results demonstrate that cardanol can effectively plasticize PLA; it is a new renewable plasticizer for PLA, holding great potential for biomedical applications.

\section{Conflicts of interest}

There are no conflicts to declare.

\section{Acknowledgements}

This work was supported by the National Natural Science Foundation of China (No. 51573098 and 51703133), the National Key Research and Development Program of China (No. 2017YFB0306902) and Technology Plan Projects of Jiaxing City, Zhejiang Province, China (No. 2015AY11015).

\section{References}

1 K. Madhavan Nampoothiri, N. R. Nair and R. P. John, An overview of the recent developments in polylactide (PLA) research, Bioresour. Technol., 2010, 101, 8493-8501.

2 K. S. Anderson, K. M. Schreck and M. A. Hillmyer, Toughening Polylactide, Polym. Rev., 2008, 48, 85-108.

$3 \mathrm{H}$. Liu and J. Zhang, Research progress in toughening modification of poly(lactic acid), J. Polym. Sci., Part B: Polym. Phys., 2011, 49, 1051-1083.

4 N. López-Rodríguez, A. López-Arraiza, E. Meaurio and J. R. Sarasua, Crystallization, morphology, and mechanical behavior of polylactide/poly( $\varepsilon$-caprolactone) blends, Polym. Eng. Sci., 2006, 46, 1299-1308.

5 A. J. Nijenhuis, E. Colstee, D. W. Grijpma and A. J. Pennings, High molecular weight poly(l-lactide) and poly(ethylene oxide) blends: thermal characterization and physical properties, Polymer, 1996, 37, 5849-5857.

6 J.-J. Han and H.-X. Huang, Preparation and characterization of biodegradable polylactide/thermoplastic polyurethane elastomer blends, J. Appl. Polym. Sci., 2011, 120, 3217-3223.

7 G. C. Liu, Y. S. He, J. B. Zeng, Y. Xu and Y. Z. Wang, In situ formed crosslinked polyurethane toughened polylactide, Polym. Chem., 2014, 5, 2530-2539.

$8 \mathrm{~W}$. Zhang, L. Chen and Y. Zhang, Surprising shape-memory effect of polylactide resulted from toughening by polyamide elastomer, Polymer, 2009, 50, 1311-1315.

9 K. S. Anderson and M. A. Hillmyer, The influence of block copolymer microstructure on the toughness of compatibilized polylactide/polyethylene blends, Polymer, 2004, 45, 8809-8823.

$10 \mathrm{~V}$. Ojijo, S. Sinha Ray and R. Sadiku, Toughening of Biodegradable Polylactide/Poly(butylene succinate-co- 
adipate) Blends via in Situ Reactive Compatibilization, ACS Appl. Mater. Interfaces, 2013, 5, 4266-4276.

11 M. Shibata, Y. Inoue and M. Miyoshi, Mechanical properties, morphology, and crystallization behavior of blends of poly(llactide) with poly(butylene succinate-co-l-lactate) and poly(butylene succinate), Polymer, 2006, 47, 3557-3564.

12 L. Jiang, M. P. Wolcott and J. Zhang, Study of Biodegradable Polylactide/Poly(butylene adipate-co-terephthalate) Blends, Biomacromolecules, 2006, 7, 199-207.

13 H. Kang, B. Qiao, R. Wang, Z. Wang, L. Zhang, J. Ma and P. Coates, Employing a novel bioelastomer to toughen polylactide, Polymer, 2013, 54, 2450-2458.

14 X. Hu, Y. Li, M. Li, H. Kang and L. Zhang, Renewable and Supertoughened Polylactide-Based Composites: Morphology, Interfacial Compatibilization, and Toughening Mechanism, Ind. Eng. Chem. Res., 2016, 55, 9195-9204.

15 N. Bitinis, R. Verdejo, P. Cassagnau and M. A. LopezManchado, Structure and properties of polylactide/natural rubber blends, Mater. Chem. Phys., 2011, 129, 823-831.

16 C. Zhang, W. Wang, Y. Huang, Y. Pan, L. Jiang, Y. Dan, Y. Luo and Z. Peng, Thermal, mechanical and rheological properties of polylactide toughened by expoxidized natural rubber, Mater. Des., 2013, 45, 198-205.

17 L. V. Labrecque, R. A. Kumar, V. Davé, R. A. Gross and S. P. McCarthy, Citrate esters as plasticizers for poly(lactic acid), J. Appl. Polym. Sci., 1997, 66, 1507-1513.

18 N. Ljungberg and B. Wesslén, The effects of plasticizers on the dynamic mechanical and thermal properties of poly(lactic acid), J. Appl. Polym. Sci., 2002, 86, 1227-1234.

19 M. Murariu, A. Da Silva Ferreira, M. Alexandre and P. Dubois, Polylactide (PLA) designed with desired end-use properties: 1. PLA compositions with low molecular weight ester-like plasticizers and related performances, Polym. Adv. Technol., 2008, 19, 636-646.

20 M. Sheth, R. A. Kumar, V. Davé, R. A. Gross and S. P. McCarthy, Biodegradable polymer blends of poly(lactic acid) and poly(ethylene glycol), J. Appl. Polym. Sci., 1997, 66, 1495-1505.

21 Z. Kulinski and E. Piorkowska, Crystallization, structure and properties of plasticized poly(l-lactide), Polymer, 2005, 46, 10290-10300.

22 R. G. Sinclair, The Case for Polylactic Acid as a Commodity Packaging Plastic, J. Macromol. Sci., Part A: Pure Appl.Chem., 1996, 33, 585-597.

23 W. M. Gramlich, M. L. Robertson and M. A. Hillmyer, Reactive Compatibilization of Poly(l-Lactide) and Conjugated Soybean Oil, Macromolecules, 2010, 43, 23132321.

24 M. L. Robertson, K. Chang, W. M. Gramlich and M. A. Hillmyer, Toughening of Polylactide with Polymerized Soybean Oil, Macromolecules, 2010, 43, 18071814.
25 M. L. Robertson, J. M. Paxton and M. A. Hillmyer, Tough Blends of Polylactide and Castor Oil, ACS Appl. Mater. Interfaces, 2011, 3, 3402-3410.

26 T. H. Zhao, Y. He, Y. D. Li, M. Wang and J. B. Zeng, Dynamic vulcanization of castor oil in a polylactide matrix for toughening, RSC Adv., 2016, 6, 79542-79553.

27 K. Zawada, A. Plichta, D. Jańczewski, H. Hajmowicz, Z. Florjańczyk, M. Stępień, A. Sobiecka and L. Synoradzki, Esters of Tartaric Acid, A New Class of Potential Double Green Plasticizers, ACS Sustainable Chem. Eng., 2017, 5, 5999-6007.

28 C. Voirin, S. Caillol, N. V. Sadavarte, B. V. Tawade, B. Boutevin and P. P. Wadgaonkar, Functionalization of cardanol: towards biobased polymers and additives, Polym. Chem., 2014, 5, 3142-3162.

29 P. Sharma, B. Lochab, D. Kumar and P. K. Roy, Sustainable bis-benzoxazines from cardanol and PET derived terephthalamides, ACS Sustainable Chem. Eng., 2015, 4, 1085-1093.

30 A. Greco, D. Brunetti, G. Renna, G. Mele and A. Maffezzoli, Plasticizer for poly(vinyl chloride) from cardanol as a renewable resource material, Polym. Degrad. Stab., 2010, 95, 2169-2174.

31 P. Yang, J. Yan, H. Sun, H. Fan, Y. Chen, F. Wang and B. Shi, Novel environmentally sustainable cardanol-based plasticizer covalently bound to PVC via click chemistry: synthesis and properties, RSC Adv., 2015, 5, 16980-16985.

32 S. Mohapatra and G. B. Nando, Cardanol: a green substitute for aromatic oil as a plasticizer in natural rubber, $R S C A d v$, 2014, 4, 15406-15418.

33 J. Chen, Z. Liu, J. Jiang, X. Nie, Y. Zhou and R. E. Murray, A novel biobased plasticizer of epoxidized cardanol glycidyl ether: synthesis and application in soft poly(vinyl chloride) films, $R S C A d v$., 2015, 5, 56171-56180.

34 I. Mihai, F. Hassouna, T. Fouquet, A. Laachachi, J.-M. Raquez, H. Ibn El Ahrach and P. Dubois, Reactive plasticization of poly(lactide) with epoxy functionalized cardanol, Polym. Eng. Sci., 2017, DOI: 10.1002/pen.24647.

35 F. Hassouma, I. Mihai, L. Fetzer, T. Fouquet, J.-M. Raquez, A. Laachachi, H. Ibn El Ahrach and P. Dubois, Design of New Cardanol Derivative: Synthesis and Application as Potential Biobased Plasticizer for Poly(lactide), Macromol. Mater. Eng., 2016, 301, 1267-1278.

36 E. W. Fischer, H. J. Sterzel and G. Wegner, Investigation of the structure of solution grown crystals of lactide copolymers by means of chemical reactions, Colloid Polym. Sci., 1973, 251, 980-990.

37 T. G. Fox, Influence of diluent and of copolymer composition on the glass temperature of a polymer system, Bull. Am. Phys. Soc., 1956, 1, 123-125.

38 J. Anakabe, A. M. Zaldua Huici, A. Eceiza, A. Arbelaiz and L. Avérous, Combined effect of nucleating agent and plasticizer on the crystallization behaviour of polylactide, Polym. Bull., 2017, 74, 4857-4886. 